\title{
"PDSA-ADHD": A Newly Reported Syndrome
}

\author{
Elizabeth G. Baxley, MD, Kevin J. Bennett, PhD, Chaiporn Pumkam, MS, \\ Sam Crutcher, MD, and M. Garrett Helms, LISW
}

\begin{abstract}
We present a satirical case report of a new syndrome, called "plan do study act-attention deficit hyperactivity disorder," or PDSA-ADHD. This syndrome is associated with the implementation of multiple simultaneous plan-do-study-act cycles as a quality improvement approach in a health care setting. This case represents a clinical warning sign of quality improvement impairment and suggests a new variant of organizational attention deficit disorder. (J Am Board Fam Med 2011;24:752-757.)
\end{abstract}

Keywords: Practice Management, Quality of Health Care

Quality improvement (QI) has been used in health care organizations for many years, and the science of improvement has accelerated since the Institutes of Medicine's Crossing the Quality Chasm report ${ }^{1}$ and the advent of the Institute for Health Care Improvement. ${ }^{2}$ Improvement methods, such as project champions, rapid cycle teams, and cycles of change, have all been adapted from industry to health care settings. ${ }^{3}$ A key component of these efforts is the Plan-Do-Study-Act (PDSA) cycle, which is used to structure improvement activities. ${ }^{3-6}$ Once an area for improvement has been identified, cycles of change follow four steps: (1) a Plan for change is identified, (2) participants Do the change, (3) outcomes are Studied, and (4) participants Act on the results. ${ }^{7}$

The use of QI methodology in health care settings has been documented, but with mixed results. Successful QI programs have been described across the health care spectrum, ${ }^{8-10}$ beginning with the seminal Breakthrough Series. ${ }^{11}$ Other studies, however, have shown that QI interventions do not impact the measured outcomes. ${ }^{12,13}$

This article was externally peer reviewed.

Submitted 18 October 2010; revised 21 March 2011; accepted 1 April 2011.

From the Department of Family and Preventive Medicine, University of South Carolina School of Medicine, Columbia, SC.

Funding: none.

Conflict of interest: none declared.

Corresponding author: Kevin J. Bennett, Assistant Professor, Department of Family and Preventive Medicine, USC School of Medicine, 3209 Colonial Drive, Columbia, SC 29203 (E-mail: kevin.bennett@sc.edu).
The successful QI and PDSA cycles have been noted in the fields of infection control, ${ }^{14}$ diabetes care ${ }^{15}$ surgery, ${ }^{16}$ and mental health. ${ }^{17}$ Lipshutz et $\mathrm{al}^{18}$ showed how PDSA cycles can be used successfully for critical care but noted many barriers to improvement, especially during the planning $(\mathrm{P})$ stage of the cycle. Others have also noted the apparent difficulty for some PDSA adopters to complete their improvement cycles, citing factors such as leadership control, poor planning, and lack of resources. ${ }^{6}$ These mixed results are not necessarily unexpected because of the difficulty in implementing and assessing changes in diverse, uncontrolled environments. ${ }^{19}$

While using PDSA cycles in our improvement efforts, we identified a new impairment syndrome; we call it "Plan Do Study Act (PDSA)-Attention Deficit Hyperactivity Disorder (ADHD)". Clinically, ADHD is associated with inattentiveness, overactivity, and impulsivity. There is evidence of this disorder at an organizational level; organizational attention deficit disorder (OADD) is characterized by an increased likelihood of missing key information when making decisions, diminished time for reflection, overreliance on simple information transactions, difficulty holding others' attention, and decreased ability to focus when necessary. ${ }^{20}$ Our particular variant, however, has not yet been reported. In this satirical case report we will describe PDSA-ADHD as a new variant of OADD, review the relevant literature to support the diagnosis, and discuss potential treatment options.

\section{Case Reports}

The Palmetto Health Family Medicine Center (FMC) is the teaching practice for the Department 
of Family and Preventive Medicine at the University of South Carolina School of Medicine. In 2004, the FMC began a period of transformation in its processes by integrating QI principles into its clinical, educational, and research missions. Teams began working on PDSA cycles targeted at clinical and operational problems, and they were initially so energized that they began looking for multiple ways to change previously well-established ways of working.

However, within 18 months, signs of impairment were apparent. Initial symptoms included multitasking on various PDSA cycles, not completing cycles, and fatigue, characterized by poor concentration, no real sense of success, and lack of commitment to sustainability. These symptoms increased in frequency and intensity until the FMC began to experience failures in accomplishing the goals of their improvement activities.

A frequent observation was that Planning was much easier than Doing, mostly because of the classic ADHD symptom of "start anxiety." Improvement teams wanted to spend longer than necessary considering every possible ramification of a planned change to be sure it was "perfect" before implementation. Work also suffered from the constant diversion of attention from the team members' ongoing day-to-day operational and educational duties to the competing stimuli of more than one performance improvement initiative being conducted. Diversion of attention because of the development of a new EHR template even persisted for one 15-month PDSA cycle before resolution. Other teams were able to move past the Planning stage to Do a cycle because of enthusiastic champions, the importance of the project, or staff support and participation. However, many often found that acquiring reliable, quantifiable data to measure the impact of changes remained elusive because of difficulties in obtaining accurate, complete data from the electronic medical record, which was caused by inconsistent documentation practices by the clinical staff. This necessitated time- and labor-intensive chart reviews to gain provider- and practice-specific quality report cards, leading to project abandonment.

Coordination between projects was often inadequate, often halting progression through PDSA cycles while at the same time creating conflicts in resource utilization. FMC leadership was unable to hold focus across areas in which changes were pro- posed because of changing priorities, inability to commit resources to projects, or inadequate assessment of the time needed for project participation. PDSA cycles were also abandoned because of uncertainty about the plan, uncertainty about how to assess effectiveness, or lack of agreement on dissemination.

Even with multiple PDSA projects in the works, any identified operational or clinical issues that were addressed pulled attention, time, and resources away from those already in action. For example, we identified a trend among patients with diabetes-they did not fill prescriptions or take their medications as instructed - and we began a PDSA cycle to address the issue. Not only did this cycle not progress past the Do stage because of a lack of consensus on how to address the issue, the team began working on another component of blood pressure monitoring. This new PDSA cycle involved using a reminder system to re-check blood pressure readings that were initially high during a visit. This, in turn, led to a discussion about developing standing orders for blood pressure monitoring, which was itself abandoned because of a lack of agreement on the key components. This succession of initiation, halting, and abandonment essentially resulted in a flood of incomplete PDSA cycles (see Table 1).

\section{Diagnosis}

Feeling the unease within the system, the FMC began to look at a differential diagnosis for its symptoms. Options included PDSA cycle addiction or codependency; distraction created by the numerous possibilities for practice improvement; and organizational depression with loss of concentration. These alone were insufficient to explain the pattern of symptoms; thus we considered whether the ailment might be explained by a known disorder. The core symptoms of ADHD, such as inattention, impulsivity, and hyperactivity, were similar to those experienced by the FMC: patients find it challenging to get organized, complete tasks, or be productive and often seem restless as they unsuccessfully try to do several things at once. ${ }^{21}$ As a result of our investigation, we devised a new diagnostic framework based on ADHD: the Baxley Criteria, which health care systems with QI programs may use for diagnostic consideration should they experience similar symptoms (see Tables 2 and 3). 
Table 1. Examples of Abandoned Plan Do Study Act (PDSA) Cycles

\begin{tabular}{|c|c|c|c|}
\hline Improvement Planned & $\begin{array}{c}\text { Stage of PDSA Cycle } \\
\text { in Which Progress } \\
\text { Was Arrested }\end{array}$ & Participants Involved & Symptoms Experienced \\
\hline $\begin{array}{l}\text { Design of new DM template } \\
\text { for EHR }\end{array}$ & Plan & Diabetes improvement team & $\begin{array}{l}\text { Multiple team members could not } \\
\text { agree on the comprehensiveness } \\
\text { of final template }\end{array}$ \\
\hline $\mathrm{BP}$ medication compliance & Do & QI team, residents & $\begin{array}{l}\text { Could not determine what to do; } \\
\text { consensus }\end{array}$ \\
\hline $\begin{array}{l}\text { Pneumovax administration and } \\
\text { tracking }\end{array}$ & Plan & QI team, one resident & $\begin{array}{l}\text { Not continued after resident } \\
\text { champion graduated }\end{array}$ \\
\hline Retinal screenings for diabetics & Study, Act & QI team, nursing & $\begin{array}{l}\text { Could not determine if first cycle } \\
\text { worked or next plan of action }\end{array}$ \\
\hline BP re-check reminder system & Act & QI team, one provider-nurse team & $\begin{array}{l}\text { Could not expand to other } \\
\text { providers }\end{array}$ \\
\hline Advanced Access Scheduling & Study & Medical director, QI team & $\begin{array}{l}\text { Could not measure demand data } \\
\text { reliably; quit trying after two } \\
\text { attempts }\end{array}$ \\
\hline Self management goal setting & Act & QI team, nursing & $\begin{array}{l}\text { Did not spread beyond two } \\
\text { physician/nurse teams }\end{array}$ \\
\hline $\begin{array}{l}\text { Microalbumin testing } \\
\text { reminders }\end{array}$ & Plan & QI team, nursing & $\begin{array}{l}\text { No agreement on standard } \\
\text { protocol }\end{array}$ \\
\hline A1c testing reminders & Study & QI team, nursing & No follow-up data collection \\
\hline $\begin{array}{l}\text { BP Monitoring Standing } \\
\text { Orders }\end{array}$ & Plan & QI team, administration, nursing & $\begin{array}{l}\text { Lack of consensus about roles, } \\
\text { duties, content }\end{array}$ \\
\hline Preclinic huddle participation & Act & QI team, nursing & $\begin{array}{l}\text { Sustainability was difficult and } \\
\text { uneven }\end{array}$ \\
\hline
\end{tabular}

DM, diabetes mellitus; EHR, electronic health record; BP, blood pressure; A1c, hemoglobin; QI, quality improvement.

\section{Treatment}

The typical management for ADHD spectrum disorders is a combination of behavioral treatment and, if appropriate, medication. ${ }^{22}$ Because we cannot advocate for systematic medication of organizational members, a focus on behavioral therapy is offered. A goal of PDSA-ADHD therapy is to encourage positive behaviors (in this case, successful completion of PDSA cycles) through a system of motivation, positive reinforcement, and negative consequences. The first step is to ensure proper

Table 2. Baxley Criteria for Plan Do Study Act (PDSA)-Attention Deficit Hyperactivity Disorder

- Multiple incomplete PDSA cycles ongoing at any one time

- Doing before planning (cycle dyslexia)

- Prolonged planning with little doing (more common in academic settings)

- A paucity of studying, resulting in insufficient acting

- Inability to complete the study of improvement cycles or tests of change

- Greater enthusiasm for tests of change than the energy or resources to carry them out

- High levels of fatigue among improvement team participants and others within the organization motivation and buy-in among PDSA cycle participants. This may take the form of a QI champion, who provides encouragement in a specific area, or the organization's leadership, which provides support and time to conduct such activities. The champion should focus on maintaining motivation among participants and minimize the effects of failures. These failures, if not handled appropriately, could lead to a dissipation of motivation, leading to a recurrence of PDSA-ADHD behaviors.

The use of behavioral modification techniques, such as reward and consequence, are insufficient to treat PDSA-ADHD symptoms; utility increases when paired with other strategies, such as assignment of a "coach" who meets with the group on a regular basis. The coach should foster group accountability and redirect the group members when they become distracted. Because most of the FMC's problems seemed to be occurring in the Do phase, the planning itself needs to be conducted in a purposeful manner to insure movement to the Do phase. A coach can hold the group to this planning guideline by using the following framework: partialize, prioritize, and plan. 


\begin{tabular}{|c|c|}
\hline \multicolumn{2}{|l|}{ A (either 1 or 2$)$} \\
\hline \multirow[t]{9}{*}{ 1. Inattention } & $\begin{array}{l}\text { Six (or more) of the following symptoms of inattention have persisted for at least } 6 \text { months } \\
\text { to a degree that is maladaptive and inconsistent with developmental level: }\end{array}$ \\
\hline & a. Often introduces a PDSA cycle without adequately collecting baseline data \\
\hline & $\begin{array}{l}\text { b. Often has difficulty completing a PDSA cycle before beginning an additional PDSA } \\
\text { cycle in another area }\end{array}$ \\
\hline & c. Unable to determine which PDSA cycle is being discussed \\
\hline & $\begin{array}{l}\text { d. Fails to complete PDSA cycles already begun, typically omitting the Study and Act } \\
\text { portions. }\end{array}$ \\
\hline & e. Often has difficulty organizing subsequent PDSA cycles \\
\hline & $\begin{array}{l}\text { f. Is reluctant to engage in tasks that require sustained or long-term change in behaviors } \\
\text { or systems }\end{array}$ \\
\hline & g. Frequently unable to remember who is in charge of each PDSA cycle \\
\hline & h. Is easily distracted by new QI ideas \\
\hline \multirow[t]{10}{*}{ 2. Hyperactivity/impulsivity } & $\begin{array}{l}\text { Six (or more) of the following symptoms of hyperactivity-impulsivity have persisted for at } \\
\text { least } 6 \text { months to a degree that is maladaptive and inconsistent with developmental } \\
\text { level: }\end{array}$ \\
\hline & i. Often contemplates new PDSA cycles while discussing current PDSA cycles \\
\hline & j. Often leaves one QI activity to participate in another ("meeting hopping") \\
\hline & k. Feels restless during Study and Act phases of PDSA cycles \\
\hline & 1. Every meeting includes at least one new PDSA cycle suggestion \\
\hline & $\begin{array}{l}\text { m. Continuing to actively pursue QI programs and activities, even during periods of rest } \\
\text { (eg, holidays) }\end{array}$ \\
\hline & n. Often talks excessively about PDSAs and QI, regardless of context \\
\hline & o. Often determines the results of a PDSA cycle before complete data collection \\
\hline & $\begin{array}{l}\text { p. Interrupting PDSA cycles (eg, a new one begins before the completion of its } \\
\text { predecessor) }\end{array}$ \\
\hline & q. Introduces interventions that interfere with existing systems and programs \\
\hline B & $\begin{array}{l}\text { Some hyperactive-impulsive or inattentive symptoms that caused impairment were present } \\
\text { in early stages of organizational change activities. }\end{array}$ \\
\hline $\mathrm{C}$ & $\begin{array}{l}\text { Some impairment from the symptoms is present in two or more settings (eg, front office } \\
\text { clinical operations, direct clinical care areas, administration, education planning). }\end{array}$ \\
\hline $\mathrm{D}$ & $\begin{array}{l}\text { There must be clear evidence of clinically significant impairment in social, academic, or } \\
\text { occupational functioning. }\end{array}$ \\
\hline
\end{tabular}

PDSA, Plan Do Study Act; QI, quality improvement.

\section{Partialize}

Look at the bricks, not the wall. Break down the task to its smallest achievable components and identify the individual steps in the process. This provides a sense that the task can be accomplished and team members can experience successes along the way.

\section{Prioritize}

In what order do the individual steps above need to accomplished? What are there the prerequisites?

\section{Plan}

A written implementation plan needs to be made, including a responsible person(s) for each step and a specific timeline. These should be inserted into a calendar (eg, "I will complete this step of the process from 1:30 to 3:30 on August 17"). Such a specific commitment helps avoid procrastination, bypasses the start anxiety, and minimizes distraction.

As the coach continues to meet with the group, they can use this framework to evaluate their success. The group will be encouraged to predict future steps, including unanticipated events, and then will repeat the partialize, prioritize, and plan steps for the next phase of the project.

Throughout the implementation of the treatment plan, there are important aspects to consider. First, those in leadership positions need to be trained to use the tools described above. Champions and other leaders should ensure that, as suc- 
Table 4. Treatment Modalities for Plan Do Study Act-Attention Deficit Hyperactivity Disorder

\begin{tabular}{|c|c|c|}
\hline Technique & Problem Addressed & Example \\
\hline \multirow[t]{5}{*}{ Motivation } & Lack of participation & Active recruitment \\
\hline & & Champion involvement \\
\hline & & Enhanced communication \\
\hline & & Identify benefits \\
\hline & & Time/resource allocations \\
\hline \multirow[t]{7}{*}{ Positive reinforcement } & Lack of positive feedback & Administrative "coaching" \\
\hline & & Recognition for efforts \\
\hline & & Administrative "celebrations" \\
\hline & & Link efforts to performance reviews/merit increases \\
\hline & Inadequate planning & Ability to link outcomes to efforts \\
\hline & & Task prioritization \\
\hline & & Tracking of tasks and timelines \\
\hline \multirow[t]{4}{*}{ Negative consequences } & Anonymity/free riding & Create specific plans, assign tasks, and publically hold accountable \\
\hline & & Link efforts to performance reviews/merit increases \\
\hline & Inertia/change resistance & Encourage leadership to facilitate changes \\
\hline & & Utilize motivation, positive reinforcement techniques listed above \\
\hline
\end{tabular}

cesses occur, they recognize and communicate these small celebrations along the way, acknowledging the individuals involved. This recognition should occur frequently in the beginning of the treatment plan and be conducted in an open and public forum to maximize the impact of the positive reinforcement. Also, the organization should consider linking actual job duties, performance reviews, or merit-based pay increases to the desired QI activities to make the process sustainable over time. Table 4 summarizes suggested treatment modalities for PDSA-ADHD.

\section{Conclusion}

Based on previous knowledge and our current observations, we believe that we have identified a variant of OADD, called PDSA-ADHD, to explain the various symptoms experienced at the FMC, including too many PDSA cycles at various stages, lack of follow-up on previous cycles, and chronic fatigue resulting from a lack of success. Feedback loops that could have been helpful were missing because data to support decision making were insufficient. Other contributors to disease progression were inadequate staffing to support QI efforts, competing faculty and staff roles, and inability to realistically assess the time and effort involved in making practice-wide changes.

We believe that this is the first report describing the PDSA-ADHD syndrome, which is likely to become more common as the efforts to improve health care quality and safety increase. Many health care practices seem to have trouble initiating QI interventions and even more trouble maintaining them. This can result from a lack of understanding of the rationale for the QI approach and inadequate training about the model for improvement. Complacency is a frequent response when members of the organization have seen QI projects started and then take months or years to complete, representing a poor use of their time for no apparent improvement. $^{11}$

We are hopeful that the proposed diagnostic criteria of PDSA-ADHD will help those involved in health care redesign to detect symptoms at an early stage so that they can use the suggested therapeutic activities to address the inattention, impulsivity, and hyperactivity that can lead to ineffectiveness and a reduction in morale among members of the organization. We hope that by raising awareness of this newly described syndrome, others will identify and manage it early, avoiding some of the same problems encountered during the acute phase of PDSA-ADHD syndrome.

\section{References}

1. Committee on Quality of Health Care in America, Institute of Medicine. Crossing the Quality Chasm: A New Health System for the 21st Century. Washington, DC: National Academies Press; 2001.

2. Kenney C. The Best Practice: How the New Quality Movement Is Transforming Medicine. New York: Public Affairs; 2008. 
3. Lighter DE. Advanced performance improvement in Health Care: Principles and Methods. Sudbury, MA: Jones \& Bartlett Publishers; 2009.

4. Deming WE. Out of the Crisis. Cambridge, MA: Massachusetts Institute of Technology, Center for Advanced Engineering Study; 1986.

5. Shewhart W. Economic Control of Quality of Manufactured Product. New York: D. Van Nostrand Company, Inc.; 1931.

6. Walley P, Gowland B. Completing the circle: from PD to PDSA. Int J Health Care Qual Assur Inc Leadersh Health Serv 2004;17(6):349-58.

7. Langley G. The improvement guide: a practical approach to enhancing organizational performance. 2nd edition. San Francisco, CA: Jossey-Bass; 2009.

8. Schouten LM, Hulscher ME, van Everdingen JJ, Huijsman R, Grol RP. Evidence for the impact of quality improvement collaboratives: systematic review. BMJ 2008;336(7659):1491-4.

9. Stevens D, Bowen J, Johnson J, et al. A multiinstitutional quality improvement initiative to transform education for chronic illness care in resident continuity practices. J Gen Intern Med 2010;25:574-80.

10. Stroud J, Felton C, Spreadbury B. Collaborative colorectal cancer screening: a successful quality improvement initiative. Proc (Bayl Univ Med Cent) 2003;16(3):341-4.

11. Kilo C. A framework for collaborative improvement: lessons from the Institute for Healthcare Improvement's Breakthrough Series. Qual Manag Health Care 1998;6(4):1-13.

12. Solberg L, Kottke T, Brekke M, et al. Failure of a continuous quality improvement intervention to increase the delivery of preventive services. A randomized trial. Eff Clin Pract 2000;3(3):105-15.
13. Solberg L, Fischer L, Wei F, et al. A CQI intervention to change the care of depression: a controlled study. Eff Clin Pract 2001;4(6):237-49.

14. van Tiel FH, Elenbaas TW, Voskuilen BM, et al. Plan-do-study-act cycles as an instrument for improvement of compliance with infection control measures in care of patients after cardiothoracic surgery. J Hosp Infect 2006;62(1):64-70.

15. Porter C, Wheatland B, Gilles M, Greenfield C, Larson A. Initiating a PDSA cycle. Improving management of diabetes in rural WA. Aust Fam Physician 2006;35(8):561-656.

16. Nakayama DK, Bushey TN, Hubbard I, et al. Using a Plan-Do-Study-Act cycle to introduce a new or service line. AORN J 2010;92(3):335-43.

17. Lynch-Jordan AM, Kashikar-Zuck S, Crosby LE, et al. Applying quality improvement methods to implement a measurement system for chronic pain-related disability. J Pediatr Psychol 2010;35(1):32-41.

18. Lipshutz A, Fee C, Schell H, et al. Strategies for success: a PDSA analysis of three QI initiatives in critical care. Jt Comm J Qual Patient Saf 2008;34(8):435-44.

19. Berwick DM. The science of improvement. JAMA 2008;299(10):1182-4.

20. Davenport TH, Beck JC. The Attention Economy: Understanding the New Currency of Business. Boston, MA: Harvard Business School Press; 2001.

21. Hales RE, Stuart CY, Glen OG. The American Psychiatric Publishing Textbook of Psychiatry. 5th edition. Washington, DC: American Psychiatric Publishing, Inc.; 2008.

22. American Academy of Pediatrics, Subcommittee on Attention-Deficit/Hyperactivity Disorder and Committee on Quality Improvement. Clinical practice guideline: treatment of the school-aged child with attention-deficit/hyperactivity disorder. Pediatrics. 2001 Oct; 108(4):1033-44. 